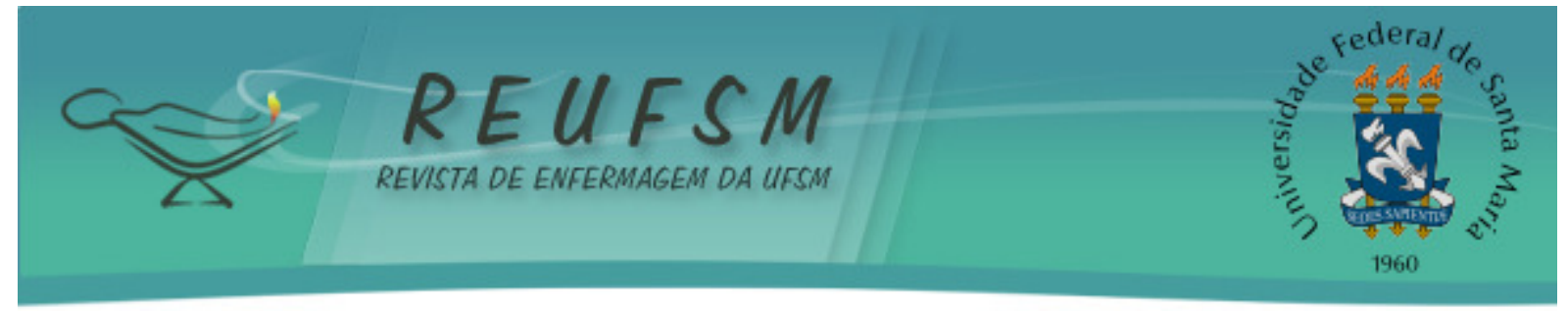

ARTIGO ORIGINAL

\title{
EDUCAÇÃO PERMANENTE COMO POTENCIALIZADORA DA GESTÃO DO SISTEMA DE SAÚDE BRASILEIRO: PERCEPÇÃO DOS GESTORES
}

\section{PERMANENT EDUCATION AS MANAGEMENT ENHANCER OF BRAZILIAN HEALTH SYSTEM: MANAGERS'S PERCEPTION}

\section{EDUCACIÓN PERMANENTE COMO POTENCIADORA DE LA GESTIÓN DEL SISTEMA DE SALUD DE BRASIL: LA PERCEPCIÓN DE LOS GERENTES}

\author{
Carine Vendruscolo ${ }^{1}$ \\ Jociele Cristina Delazere ${ }^{2}$ \\ Denise Antunes de Azambuja Zocche ${ }^{3}$ \\ Daiana Kloh ${ }^{4}$
}

Doi: $10.5902 / 2179769220229$

RESUMO: Objetivo: identificar as percepções dos gestores de saúde no Sistema Único de Saúde (SUS) em relação à Educação Permanente em Saúde (EPS) na Macrorregião Extremo Oeste de Santa Catarina, Brasil. Método: estudo descritivo, exploratório e qualitativo, desenvolvido com gestores de saúde que integram uma região do extremo oeste do estado de Santa Catarina. Foram entrevistados 21 gestores de saúde. Os dados foram tratados por meio da análise de conteúdo. Resultados: Destaca-se a ausência de formação na área da saúde, entre os gestores. Há equívocos referentes ao uso das terminologias educação permanente e continuada em saúde, contudo, os gestores reconhecem a educação permanente como busca de conhecimento a partir da prática laboral e como ferramenta de gestão. Considerações finais: a educação permanente vem sendo incorporada, gradativamente, ao trabalho dos profissionais, sobretudo, da enfermagem, ao reconhecer seu papel na liderança dos processos de gestão em saúde.

Descritores: Educação continuada; Políticas públicas; Sistema único de saúde.

ABSTRACT: Aim: to identify managers of the Brazilian health system's perception regarding the continuing health education in the extreme West macroregion of Santa Catarina, Brazil. Method: descriptive, exploratory qualitative study, developed with health managers that integrate a westernmost region of the state of Santa Catarina. Twenty-one health managers were interviewed. The data was analyzed by the content's analysis proposal. Results: Noteworthy is the lack of training in health among the managers. There are misconceptions regarding the use of the terminologies permanent and continuing education in health, however, managers recognize the continuing education as a pursuit of knowledge from the working practice and as a management tool. Final considerations: permanent education has been incorporating, gradually, the work of professionals, especially in the nursing area, by recognizing their role in the leadership of health management processes.

Keywords: Continuing education; Public policy; Unified health system.

\footnotetext{
1 Enfermeira, Doutora em Enfermagem. Docente da Universidade do Estado de Santa Catarina (UDESC). Chapecó/Santa Catarina/Brasil. E-mail: carine.vendruscolo@udesc.br

${ }^{2}$ Enfermeira, Especialista em Saúde da Família. Servidora Municipal. São Jose do Cedro/Santa Catarina/Brasil.

E-mail: E-mail: jociele_enf@yahoo.com.br

3 Enfermeira, Doutora em Enfermagem. Docente da Universidade do Estado de Santa Catarina (UDESC). Chapecó/Santa Catarina/Brasil. E-mail: denise9704@gmail.com

4 Enfermeira, Doutora em Enfermagem. Membro do Grupo de Pesquisa em Educação em Enfermagem (PEN/UFSC). Florianópolis/Santa Catarina/Brasil. E-mail: daianakloh@gmail.com
} 


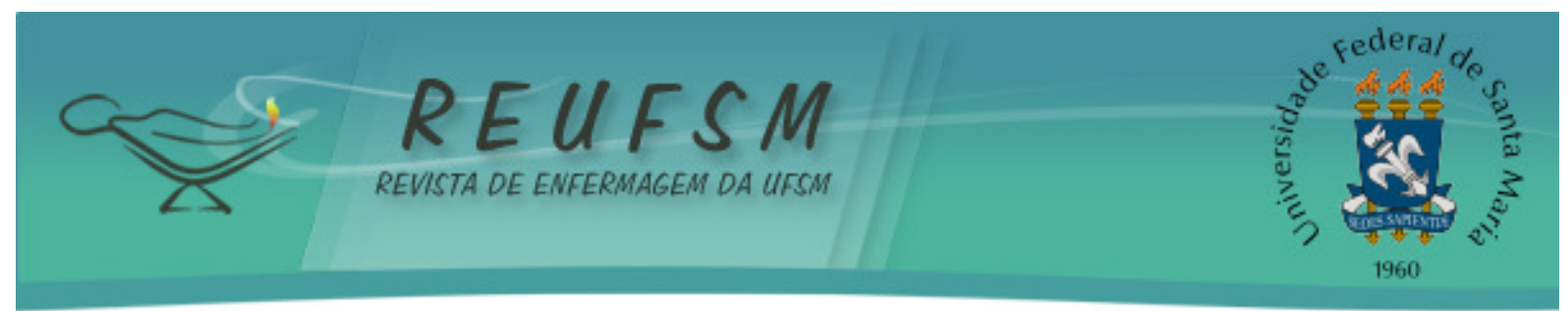

RESUMEN: Objetivo: identificar las percepciones de los directivos del sistema único de salud en relación a la educación para la salud continua. Método: estudio descriptivo, cualitativo y exploratorio, desarrollado con los administradores de salud de la región occidental del estado de Santa Catarina. Se entrevistó 21 gerentes. Los datos fueron analizados utilizando el análisis del contenido. Resultados: se destaca la ausencia de formación en materia de salud entre los administradores. Hay conceptos erróneos con respecto al uso de la terminología permanente y la formación continua en materia de salud, sin embargo, los directivos reconocen la educación continua como búsqueda del conocimiento en la práctica de trabajo y como herramienta de gestión. Consideraciones finales: la educación permanente se ha incorporado poco a poco en el trabajo de los profesionales, especialmente de enfermería, reconociendo su papel en la dirección de los procesos de gestión de la salud.

Descriptores: Educación continua; Políticas públicas; Sistema único de salud.

\section{INTRODUÇÃO}

A Política de Educação Permanente em Saúde (PNEPS) apresenta como objetivo a formação e o desenvolvimento dos trabalhadores para o setor de saúde, por meio de constantes processos educativos, ancorados à realidade de trabalho e ao contexto social dos sujeitos. Essa política contribui para transformar e qualificar a atenção à saúde, a organização das ações e dos serviços e as práticas de saúde e pedagógicas. ${ }^{\top}$ A PNEPS foi instituída em 2004, revisada em 2007 e, atualmente, sua condução ocorre por meio das Comissões Intergestores Regionais (CIR) com a participação das Comissões Permanentes de Integração Ensino-Serviço (CIES). ${ }^{2}$

As CIR são compostas pelo conjunto de gestores municipais do Sistema Único de Saúde (SUS) de uma determinada região, o representante do gestor estadual, e devem considerar as especificidades locais, bem como, a PNEPS para elaborar o plano de ação de educação permanente, coerente com as demandas regionais e os aspectos de Educação Permanente em Saúde (EPS) apresentados nos planos de saúde municipais e estaduais. ${ }^{2}$ Essa configuração implica no fortalecimento da gestão democrática, com participação dos trabalhadores, assegurando a valorização e fortalecendo relações de trabalho no intuito de garantir a atuação solidária e de qualidade. ${ }^{3}$

A reflexão sobre o processo de trabalho em saúde produzida de modo dialógico, coletivo e inclusivo, é pressuposto para a possibilidade de transformação da realidade. Nesse contexto, os gestores assumem importante papel, de modo a fomentar e (re)significar as práticas e teorias relacionadas a organização do trabalho e educação. Isso ocorre por meio de intervenções junto aos trabalhadores que levam em consideração as experiências e problemas identificados no cotidiano laboral. É nessa direção que a CIR e CIES tornam-se importantes veículos para criar espaços de discussão, em que a busca do consenso, das trocas e da produção do conhecimento no coletivo são dispositivos que visam garantir o direito à singularidade das pessoas.

Com base nessas reflexões, o presente estudo parte da seguinte pergunta de pesquisa: Qual é a percepção dos gestores do SUS em relação à EPS? Acredita-se que as percepções sobre a PNEPS e as ações de EPS que são desenvolvidas, em âmbito local, pelo gestor de determinada região, serão decisivas no desenvolvimento dessa Política. Ainda, considera-se a necessidade constante de atualização epistemológica, diante das mudanças tecnológicas de nosso tempo, o que implica na reflexão sobre novas estratégias para aprimorar os conhecimentos de profissionais, gestores e estudantes da área da saúde sobre as possibilidades e práticas educativas, sobretudo, a educação permanente. Cumpre destacar a relevância do estudo para a área de enfermagem, tendo em vista os crescentes 


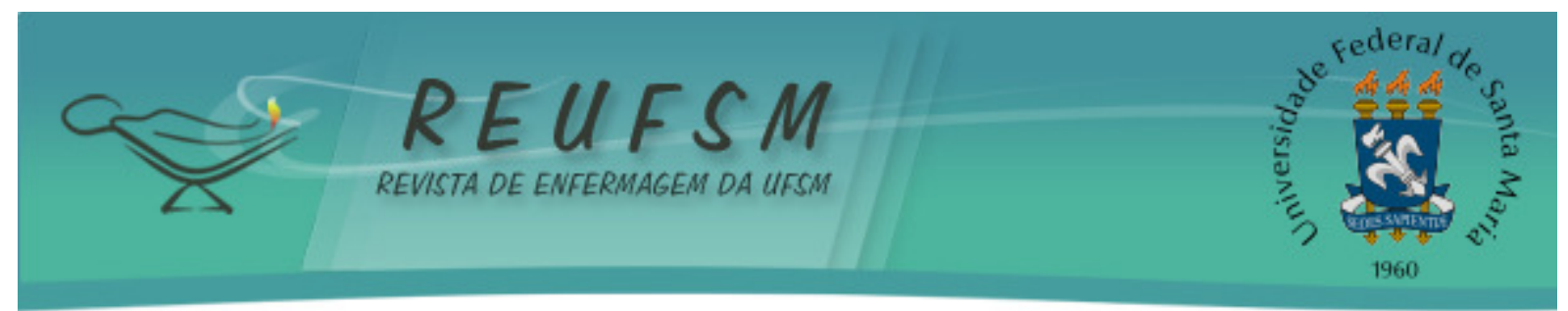

desafios ligados à gestão que permeiam o desenvolvimento da profissão no Brasil, e que exigem competências como a comunicação, a liderança, a tomada de decisões e o gerenciamento, habilidades que precisam ser promovidas na formação e fortalecidas mediante processos de educação permanente. Assim, a pesquisa objetiva identificar as percepções dos gestores de saúde no SUS em relação à EPS na Macrorregião Extremo Oeste de Santa Catarina, Brasil.

\section{MÉTODO}

Trata-se de um estudo qualitativo, descritivo e exploratório, desenvolvido com gestores de saúde do SUS que integram a CIR da Macrorregião de Saúde Extremo Oeste de Santa Catarina, Brasil. Vale destacar que a região é composta por 30 municípios.

0 número de participantes da pesquisa foi delimitado pelo critério de saturação dos dados, ${ }^{4}$ totalizando 21 , dentre estes, três gestores estaduais e 18 gestores municipais. Como critérios de inclusão dos participantes, estes deveriam ter desempenhado a atividade de gestor municipal e/ou estadual por, no mínimo, três meses, entre os anos de 2013 e 2014.

Para a coleta de dados utilizou-se a entrevista semiestruturada com os gestores, mediante um instrumento guia. As questões tratavam das suas percepções sobre EPS e ações desenvolvidas no âmbito da PNEPS. Os dados foram coletados em junho e julho de 2014 e as entrevistas foram realizadas em ambiente privado, no estabelecimento de trabalho do gestor, de acordo com agendamento prévio e, mediante seu livre consentimento. Tiveram duração média de 30 minutos, foram gravadas em áudio e transcritas na íntegra.

As informações foram analisadas a partir da proposta de análise operativa. ${ }^{5}$ Após a transcrição das entrevistas, foram extraídas as unidades de registro, caracterizadas por frases com significado temático em relação ao objeto, indicando temas recorrentes destacáveis das percepções relatadas pelos gestores, que foram reagrupados em categorias, a partir dos domínios semelhantes a todas as entrevistas. Por fim, os resultados foram discutidos à luz dos pressupostos e referenciais conceituais que conformam a PNEPS. A análise dos dados iniciou concomitantemente à coleta dos mesmos e resultou no constructo que será discutido, posteriormente.

Esta pesquisa foi aprovada pelo Comitê de Ética em Pesquisa da Universidade do Estado de Santa Catarina (UDESC), sob o número 649.101/2014. A fim de preservar a identidade dos participantes, ao revelar os discursos dos mesmos, seus nomes, bem como dos municípios de origem foram omitidos e utilizaram-se as letras GM, para gestor municipal e GE, para gestor estadual, seguida pelo número da entrevista correspondente: GM1, GE1, e assim por diante.

\section{RESULTADOS}

Percepção dos gestores de saúde acerca da EPS: prática reflexiva pautada no cotidiano do serviço

A idade dos gestores variou entre 26 e 53 anos. Um terço (7), tinha ensino médio completo, quatro (4) ensino superior na área da saúde, os demais (10) ensino superior em outras áreas do conhecimento. Dos que tinham ensino superior na área da saúde, todos apresentavam especialização respectivamente, em Gestão Financeira e Controladoria, Farmácia Hospitalar e Saúde Coletiva, Saúde Pública e Citologia Clínica. Quanto ao sexo, a maioria são mulheres (13) os demais (8) homens. Sobre o tempo de gestão, variou entre 


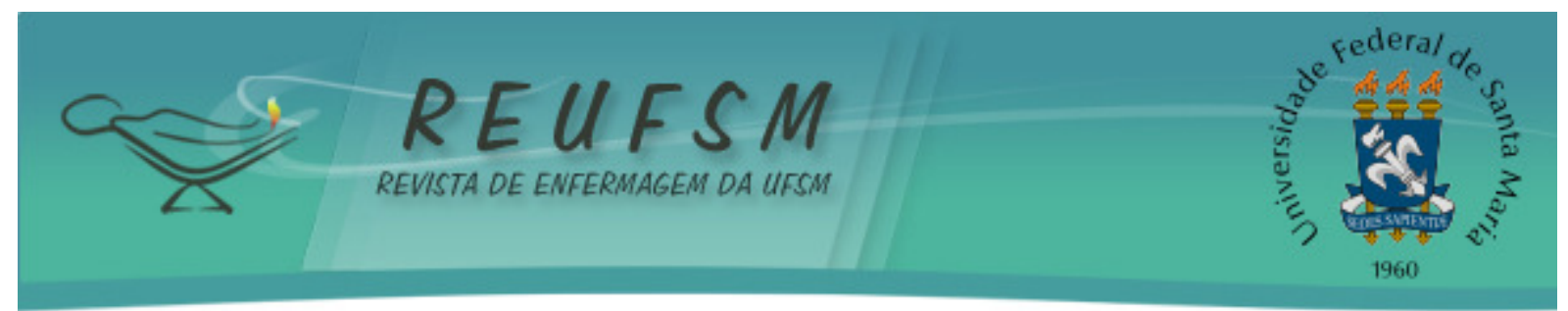

um ano e meio a onze anos. Destaca-se, no perfil, que os gestores possuem pouca inserção na área da saúde. Ainda, os dados indicam um aumento de mulheres nos cargos de gestão. Essa variedade, contudo, é esperada, pois se sabe que a rotatividade de gestores e profissioanais nos municípios e equipes de saúde é grande.

Os gestores reconhecem a EPS como uma ferramenta importante na busca de conhecimento, por meio de cursos e atualizações, porém, também como um processo que necessita melhorar:

Educação permanente em saúde na minha visão é uma ação importantíssima [...] uma excelente estratégia. (GE20)

Eu acho bem interessante educação permanente, na unidade de saúde, toda equipe não pode parar, todos têm que estar estudando para se atualizar. (GM8)

Eu vejo a educação permanente como uma necessidade ainda a ser compreendida melhor, não só da parte do gestor, mas da parte do próprio servidor, do próprio profissional da saúde como busca. (GM9)

Passados mais de 10 anos da implantação da PNEPS, ainda é grande o desafio para atuar em conformidade com a política, como descrito nas falas dos gestores em relação a sua compreensão sobre o processo:

Educação Permanente seria novas atualizações, novos conhecimentos sobre a área da saúde. Os profissionais [...] sempre têm que estar se atualizando. Hoje tem tantas ferramentas para se atualizar: o próprio Telessaúde [...] palestras interessantes de atualização. (GM12)

Estar sempre atualizado, participando de cursos, de palestras $e$ informações, principalmente. (GM13)

Contudo, os gestores reconhecem a EPS como um dispositivo fundamental na mudança dos processos de trabalho. Em outros discursos, observam que não se trata de momentos pontuais, o processo de EPS é construído no cotidiano:

É o dia-a-dia, não é só um dia por semana, mas todo dia a gente tem que estar em educação permanente, dentro da equipe atendendo um paciente a gente já está em educação permanente, a gente está sempre aprendendo. (GM15)

A educação permanente é algo que vem se falando há muito tempo e a gente vem colocando em prática no nosso dia-a-dia, nós como gestores.[...]você tem sempre que estar se atualizando, às vezes você está trabalhando numa realidade do teu dia-a-dia que é bastante construtiva e vai te trazer um conhecimento [...].(GE16)

\section{DISCUSSÃO}




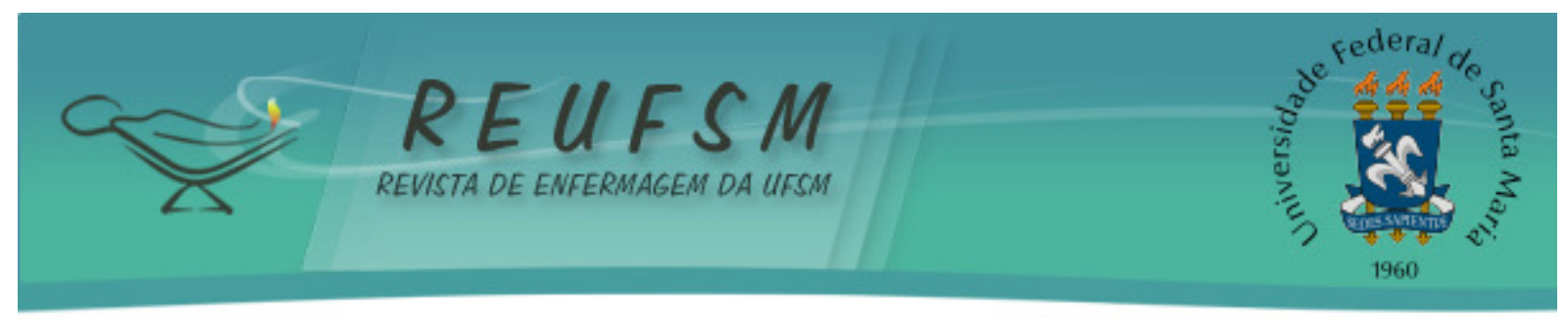

Os dados demonstram que os participantes possuem formação em diferentes campos de atuação, o que pode facilitar o processo gerencial, contudo a gestão em saúde pública é complexa e exige habilidades e qualificação contínuas. Nessa ótica, considera-se importante a formação profissional do gestor, qualificando-o para a gestão do Sistema de Saúde brasileiro e garantindo o acesso aos serviços, a qualidade da atenção, a integralidade das ações e a consolidação do SUS. ${ }^{6}$

Observa-se que a maioria dos gestores possui ensino superior, todavia, poucas especializações na área de saúde pública. Isso era esperado, pela forma de indicação para essa função. Contudo, a baixa procura por qualificação nessa área específica pode impactar na forma como hoje é ofertada a cobertura e o processo de trabalho em saúde. Assim, questiona-se: ocorre, de fato, a reflexão sobre o potencial da EPS no cotidiano dos serviços públicos, voltado a realidade da população, mesmo quando os gestores apresentam formações tão diversas? Essas especializações atendem as necessidades loco regionais de saúde?

Destaca-se a PNEPS como uma das alternativas viáveis de mudanças no espaço de trabalho, por cogitar formas diferenciadas de educar e aprender. A Política propõe transcender o tecnicismo e as capacitações pontuais, instigando a participação ativa dos sujeitos no processo de educação, assim como o desenvolvimento da capacidade crítica e criadora dos participantes. A educação permanente busca transformar as práticas profissionais existentes por meio de respostas construídas a partir da reflexão de trabalhadores, estudantes e demais atores sociais. ${ }^{7}$

Associado a essa realidade, ressalta-se a ideia de que o gestor e demais profissionais de saúde necessitam buscar qualificação para o exercício da gestão, o que vem sendo reforçado via estratégias indutoras do Ministério da Saúde, como Especialização em Gestão do Trabalho e da Educação na Saúde, Curso de Qualificação de Gestores, dentre outros. Segundo o Manual de Orientação para Gestores Municipais de Saúde ${ }^{8}$, para a consolidação do Sistema de Saúde é preciso reconhecer a implicação do perfil dos atores que assumem e conduzem as diversas instâncias de governo, ou seja, a organização do sistema exige não só o empenho do gestor, mas a articulação, a parceria e, principalmente, a visão intersetorial da saúde.

A intersetorialidade está, ou deveria estar, afinada com as demandas de saúde, que são diferentes das que ocorriam em décadas anteriores, cujo pressuposto de atenção à saúde baseava-se exclusivamente no conhecimento técnico, específico na área. Atualmente, além do conhecimento, é necessário desenvolver habilidades permeadas por mudanças práticas na atitude, no contexto do trabalho. 0 gestor de saúde deverá alinhar a teoria à necessidade da prática e é compreendido como o indivíduo que assume posição de liderança dentro do Sistema de Saúde. ${ }^{9}$ Desse modo, a formação e o compromisso social dos gestores são pilares para inserir no campo da prática as diretrizes da PNEPS e assim, garantir e ampliar a cobertura à saúde e a qualidade da formação, pautadas nas necessidades da população.

Nesse cenário, vale lembrar a atuação imprescindível da enfermagem no alcance das metas de cobertura universal à saúde em todos os níveis de assistência, embora somente um dos gestores tivesse formação na área. Contudo, outros estudos demonstram que a profissão vem ganhando destaque nessa função. ${ }^{10}$

O Ministério da Saúde brasileiro, por meio do Departamento de Gestão da Educação na Saúde, vem atuando no sentido de reorientar e ampliar a formação dos profissionais da saúde para a área da Atenção Primária, com vistas a aumentar a resolutividade da atenção no âmbito do SUS, vigente no País. A referida formação também faz parte da PNEPS, que salienta aspectos como o conceito ampliado de saúde; a utilização 


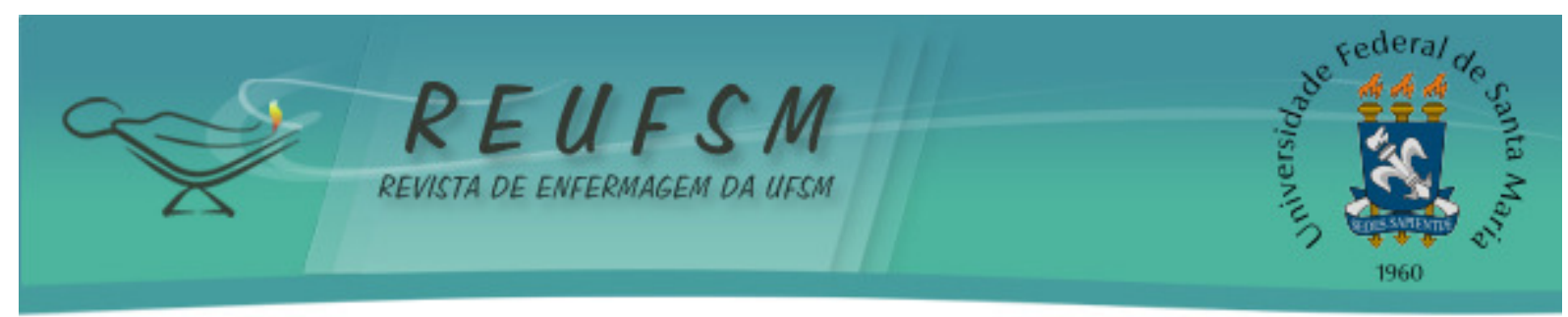

de metodologias ativas de ensino-aprendizagem que considerem o trabalho como base para as atividades; o trabalho em equipe multiprofissional e interdisciplinar, a integração entre o ensino e os serviços de saúde; o aperfeiçoamento da atenção integral à saúde e a qualificação da gestão. ${ }^{11}$

Para que o gestor consiga integrar a teoria com as necessidades da prática, o mesmo deve ter clareza sobre os significado da educação permanente. Embora com exceções e variações, um dos resultados encontrados sinaliza para uma notável homogeneidade de entendimentos e práticas sobre educação permanente, tipos de atividades desenvolvidas e percepção de demandas. Em razão dessa relativa homogeneidade, da extensão dos dados, resultados e temas suscitados pela pesquisa e devido ao espaço restrito, serão priorizados e discutidos neste momento, essas convergências. Uma delas é que há uma associação da EPS à atualização de conhecimentos.

A EPS aposta na formação como parte de um projeto de transformação, com mudanças na forma de compreender a educação e a construção de saberes. Permite que os profissionais reflitam acerca das experiências vividas nos serviços de saúde, estabelecendo relações da teoria com a realidade vivenciada, possibilitando que suas ações possam ser transformadas e realizadas a partir do processo prática-reflexão-ação. ${ }^{12}$ Destaca-se que a EPS está centrada no contexto cotidiano do processo de trabalho, na sua valorização como fonte de conhecimento, na articulação entre atenção à saúde, gestão e controle social; voltada à multiprofissionalidade e à interdisciplinaridade, com estratégias de ensino contextualizadas e participativas. Já a educação continuada está direcionada para a concepção de educação como transmissão da informação e para a valorização da ciência como fonte do conhecimento. Tende a ser pontual, fragmentada e construída de forma não articulada à gestão, à atenção e ao controle social, com enfoque nas categorias profissionais e no conhecimento técnico-científico de cada área, com ênfase em cursos e treinamentos construídos, tendo por base o diagnóstico de necessidades das categorias. ${ }^{13}$ Nessa direção, a educação continuada privilegia uma metodologia voltada a cursos pontuais, que geralmente, não estimula a autonomia do trabalhador, importante para a tomada de decisões no que concerne, não só a posturas diferentes do que estabelecem os protocolos técnicos dos cursos de formação, como também aos enfrentamentos da gestão.

Neste sentido, o estudo revela que os gestores situam-se em torno de um ideário centrado em ações de educação em saúde de cunho individual (e grupal) de tendência bancária ${ }^{14}$, em que a transmissão verticalizada de conhecimentos predomina. Os dados mostram um certo equívoco sobre o sentido da educação permanente e continuada, pois expressões como: "você tem sempre que estar se atualizando", "Educação Permanente seriam novas atualizações", revelam um ideário no qual o aprender parte de um processo individual do profissional da saúde, ou seja, passa por experiências tradicionais de transmissão de saberes de alguém que sabe e transmite para quem não sabe.

No entanto, sabe-se que, diferente da percepção revelada no estudo, a EPS pressupõe uma metodologia diferenciada de aprendizado, que inclui a troca de saberes/fazeres com a intersecção entre o preceito teórico e a reflexão das práticas diárias, na qual a teoria subsidia a prática e a prática fundamenta a teoria, continuamente, realimentando-se e interativamente, construindo novos conhecimentos, sedimentando-os, de acordo com as necessidades pessoais e institucionais, sem centralizar a produção de saberes em um único responsável. A EPS utiliza-se de estratégias que buscam a reflexão crítica sobre as práticas do serviço, sendo, por si só, uma ação 


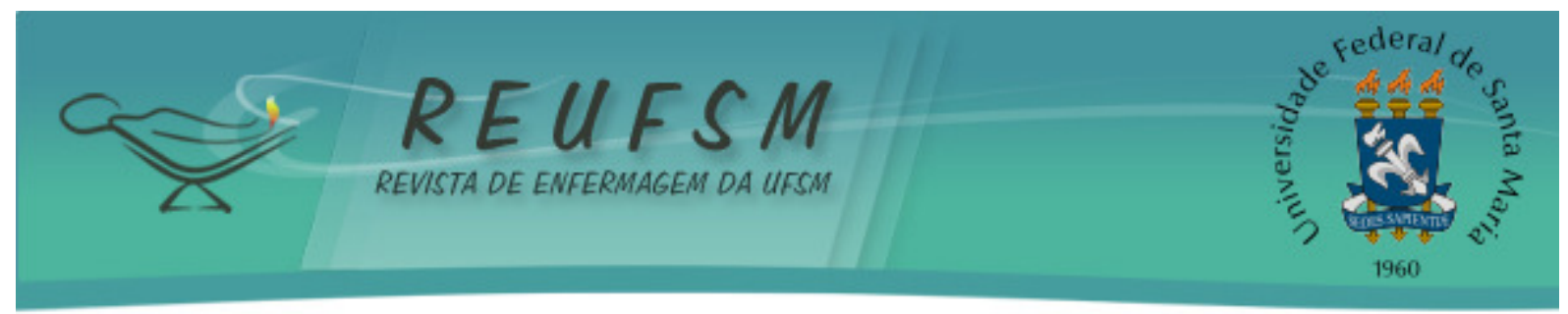

educativa voltada ao trabalho que possibilita transformações nas relações, nos processos de trabalho, nas condutas, nas atitudes, nos profissionais e na equipe. ${ }^{15}$

Torna-se importante ressaltar que o conceito de EPS foi adotado pelo MS com o objetivo de tornar a rede pública de saúde uma rede de ensino/aprendizagem no exercício do trabalho, preenchendo as lacunas existentes no processo de formação, transformando as práticas profissionais e a organização do trabalho. ${ }^{16}$

Nesse contexto, o município deve ser valorizado como espaço potencializador de redes de participação social e favorecer a articulação cooperativa e solidária entre as gestões municipais e a gestão estadual, conformando um modelo regionalizado, o que representa a possibilidade de construção da atenção integral à saúde e garantia do acesso e cobertura universal de saúde. Essa tarefa implica no fortalecimento da gestão democrática com a participação dos trabalhadores, assegurando a valorização profissional e fortalecendo as relações de trabalho, no intuito de garantir a atuação solidária, humanizada e de qualidade. ${ }^{3}$

Embora os gestores reconheçam a importância da EPS como estratégia de fortalecimento das equipes e qualificação da assistência em saúde, operacionalmente, ainda não têm clareza quanto aos seus instrumentos e estratégias como potenciais transformadores das práticas profissionais e para a organização do trabalho. É, sobretudo, nessa direção que os gestores necessitam transcender à compreensão de que a simples transmissão de conhecimentos e saberes técnicos, garantiria o aprendizado e tampouco as atualizações, amplamente mencionadas no estudo. Estas, por si só, não garantem as transformações necessárias para qualificar a atenção a saúde, preparar os profissionais para as demandas cotidianas e constantes dos processos de gestão e, ainda garantir uma educação condizente com as demandas dos serviços de saúde e necessidades da população. O estudo revelou que a proposta de EPS carece estar sintonizada com as diretrizes preconizadas na PNEPS e com as necessidades dos sujeitos envolvidos no processo de trabalho, articulada com 0 momento vivido no cotidiano da práxis.

Os dados trazem que a EPS seria uma forma de capacitação, contudo parte dos gestores participantes do estudo reconhecem que esta capacitação deva ser direcionada ao dia-a-dia, concebendo o aprendizado no cotidiano do serviço. Esta ressalva dos gestores vem ao encontro de um dos pressupostos da EPS, ou seja, a aprendizagem a partir do trabalho, e que o cotidiano é reconhecido como tema para a produção de saberes e resolução de problemas. Sob esta ótica, propõe-se a (re) visão do processo laboral, problematizando com a equipe de saúde e gestores as dificuldades vivenciadas, apropriando-se do conhecimento teórico-prático, a fim de aumentar as oportunidades de aprendizagem no cotidiano e impulsionar constantes melhorias, repercutindo, inclusive na qualidade da assistência prestada à população. Esse processo de aprendizado no e a partir do trabalho em ato, propicia reflexões críticas frente às necessidades identificadas nos ambientes, bem como nas ações do dia-a-dia, proporcionando mudanças mediante a implementação dos conhecimentos adquiridos e assim, resulta em melhoria da qualidade dos serviços de saúde ofertados ${ }^{17}$. Tal ideário reforça que se desenvolva a EPS a partir dos problemas enfrentados na realidade, a partir dos conhecimentos e experiências dos sujeitos e das necessidades sentidas e evidenciadas na consecução de suas atribuições.

No presente estudo, fica evidenciado que os gestores reconhecem a implicação dos processos formativos no cotidiano do trabalho em saúde. A necessidade de processos formativos emerge dos problemas enfrentados no mundo do trabalho, conhecimentos e experiências dos trabalhadores e das necessidades sentidas e evidenciadas na execução de suas atribuições. Contudo, mesmo reconhecendo essa importância, identificou-se a 


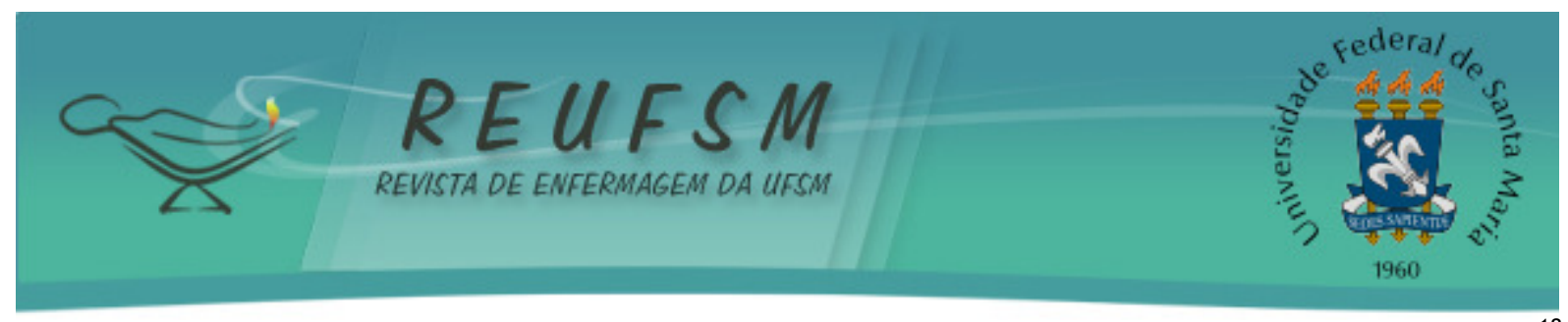

ausência de práticas de EPS nos municípios investigados. Esse dado corrobora com estudo ${ }^{18}$ que, ao analisarem a aprendizagem-trabalho dos profissionais de equipes de saúde, identificaram a pouca relação e utilização da educação permanente entre gestores.

O SUS, pela sua dimensão e amplitude, aparece na arena dos processos educacionais de saúde como um lugar privilegiado para o ensino e a aprendizagem, especialmente os cenários de atenção à saúde. Educar "no" e "para o" trabalho é o pressuposto da proposta de EPS. Os lugares de produção de cuidado, visando integralidade, corresponsabilidade e resolutividade são, ao mesmo tempo, cenários de produção pedagógica, pois concentram o encontro criativo entre trabalhadores e usuários. ${ }^{16}$

O que está em jogo na educação permanente é um trabalho ou um locus de trabalho exposto à transformação ou à modificação, porque deseja construir a integralidade pela rede, fomentando o diálogo sobre o que se faz individualmente ou em conjunto, e estabelecendo diretrizes para a prática coletiva. A EPS requer redes de conversação com os outros, que não compartilham necessariamente o mesmo ambiente físico, mas constroem a prática no coletivo. ${ }^{19}$ Nessa direção, cumpre destacar que o ideário do quadrilátero da formação para a saúde (ensino, gestão, atenção e controle social) ${ }^{17}$, com vistas à gestão da educação na saúde no âmbito do SUS, pressupõe que cada face, ilustrada pela figura, estabeleça fluxos e interlocutores específicos em espaços-tempos e com motivações diferentes, numa trama de conexões.

A EPS, como percebida por alguns gestores entrevistados nesse estudo, permite que os profissionais reflitam acerca de suas experiências vividas nos serviços de saúde, estabelecendo relações da teoria com a realidade vivenciada, possibilitando que suas ações possam ser transformadas e realizadas a partir do processo prática-reflexãopráxis. $^{14}$

As atuais demandas do Sistema de Saúde brasileiro requerem da formação dos profissionais de saúde, a adequação de conhecimentos e habilidades relacionados à gestão e gerência. Nessa direção, as Diretrizes Curriculares Nacionais (DCN) para a área da saúde, aprovadas em $2001^{20}$, orientam a formação de profissionais generalistas, humanistas, críticos e reflexivos, capazes de intervir sobre problemas recorrentes no perfil epidemiológico regional, com responsabilidade e compromisso social. Para tanto, no que tange à enfermagem, são necessárias competências como a comunicação, a liderança, a tomada de decisões e o gerenciamento, habilidades que devem ser promovidas e fortalecidas não apenas na formação, mas como processo de educação permanente no cotidiano, com base nas demandas da vida profissional. ${ }^{3}$ Fomentar o desenvolvimento de tais competências durante a graduação, e mesmo nos processos de EPS, é uma iniciativa que reflete na compreensão do enfermeiro profissional de saúde sobre seu papel de gestor e líder, como membro de uma equipe multiprofissional, além de possibilitar o reconhecimento de demandas formuladas por gestores dos serviços de saúde de uma determinada região.

\section{CONSIDERAÇÕES FINAIS}

O estudo contribuiu para o conhecimento da percepção dos gestores de saúde no âmbito do sistema de saúde brasileiro sobre EPS, e para a compreensão de como essa Política contribui para os processos de gestão na garantia do acesso à saúde. Além disso, foi possível conhecer o perfil dos gestores de saúde que compõem a CIR Extremo Oeste de Santa Catarina.

A EPS foi percebida como busca pelo conhecimento, por meio de cursos e atualizações na área, não mencionando sua utilização como possibilidade para a transformação da práxis, no cotidiano do processo laboral. Isso aponta para um 


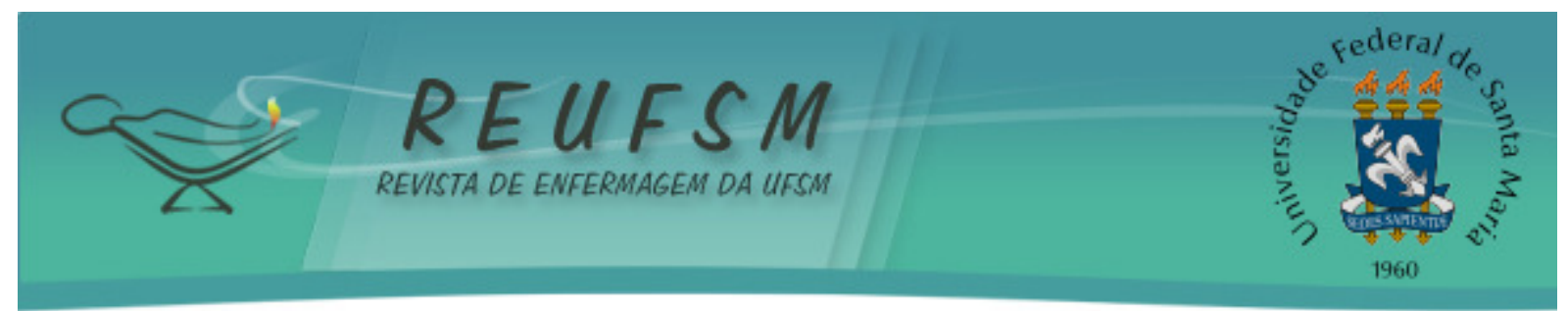

desencontro entre os termos educação permanente e educação continuada em saúde. Muitas vezes, a EPS é percebida como adequação de técnicas, revisão de protocolos, instituição de diretrizes ou capacitação de trabalhadores.

Por fim, os gestores de saúde reconhecem a EPS como uma ferramenta de gestão importante e que está gradativamente sendo incorporada ao trabalho dos profissionais. A implementação de ações de educação no âmbito do trabalho em saúde constitui-se em um dos mais sérios desafios para os gestores dos serviços. Nota-se que existe preocupação por parte dos gestores em oferecer e garantir aos profissionais o acesso a ações de EPS. E é claro que o contato com o ideário da Política contribui para a ampliação das perspectivas, mas esse contato e a crítica à educação bancária devem ser explorados por meio de arranjos institucionais de trabalho e apoio a ele, movimentos educativos que sejam promovidos pelos níveis municipais ou loco-regionais. Nesse caso, certamente, serão mais profícuos ao aproximarem-se dos locais de trabalho e ao apoiarem o manejo, interpretação, problematização e intervenção na própria realidade.

Assim, a educação permanente e sua discussão entre gestores, constitui-se em instrumento privilegiado de contribuição para o incremento da qualidade da análise da realidade e da construção de ações locais de cuidado, num contexto de democratização das relações de trabalho e de participação dos trabalhadores. Poderá auxiliar ainda mais se ancorada em outra percepção, que não a bancária e hierárquica clássica dos processos de educação e de trabalho, promovendo o empoderamento comunitário dos profissionais e facilitando o nascimento da compreensão do que seja isso em relação aos usuários.

Os gestores têm um papel fundamental no sentido de propiciar e garantir processos de EPS e de aprendizagem significativa, por meio de discussões problematizadoras acerca das necessidades identificadas em seus ambientes de trabalho, nas ações do cotidiano, e assim proporcionar mudanças e efetivar a operacionalização dos conhecimentos adquiridos, a fim de resultar em melhoria da qualidade da atenção e da produção de saúde, em direção à cobertura universal.

Destaca-se o potencial da EPS para os processos de qualificação do trabalho em saúde, de desenvolvimento profissional e, antes ainda, de garantia do SUS como direito social. Espera-se que este estudo fomente a reflexão de gestores, instituições formadoras e profissionais da saúde sobre a potencialidade da EPS no fortalecimento das redes de atenção e para a qualidade da assistência.

\section{REFERÊNCIAS}

1. Brasil. Ministério da Saúde. Portaria $n^{\circ}$ 1.996, de 20 de agosto de 2007. Dispõe sobre as diretrizes para a implementação da Política Nacional de Educação Permanente em Saúde. Diário Oficial da União, Brasília; 2007 ago 22. Seção 1, p. 34-8.

2. Brasil. Presidência da República. Casa Civil. Decreto n 7.508, de 28 de junho de 2011. Regulamenta a Lei $\mathrm{n}^{\circ} 8.080$, de 19 de setembro de 1990, para dispor sobre a organização do Sistema Único de Saúde, o planejamento da saúde, a assistência à saúde e a articulação interfederativa, e dá outras providências [Internet]. 2011[acesso em 2013 jul 3]. Disponível em: http://www.planalto.gov.br/ccivil_03/_Ato2011-2014/2011/Decreto/D7508.htm.

3. Kleba ME, Krauzer IM, Vendruscolo C. O planejamento estratégico situacional no ensino da gestão em saúde da família. Texto \& Contexto Enferm. 2011;20(1):184-93.

4. Fontanella BJB, Luchesi BM, Saidel MGB, Ricas J, Turato ER, Melo DG. Amostragem em pesquisas qualitativas: proposta de procedimentos para constatar saturação teórica. Cad Saúde Pública. 2011;27(2):389-94. 


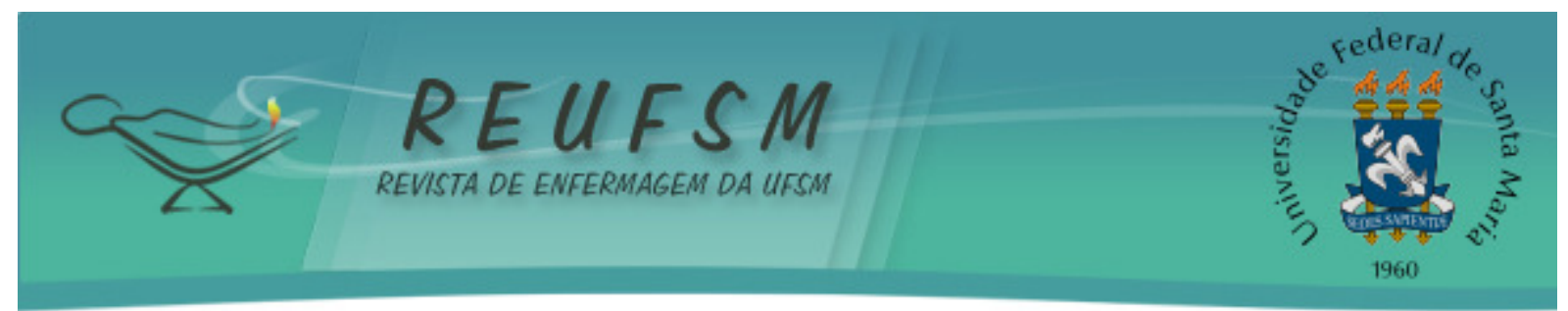

5. Minayo MCS. O desafio do conhecimento: pesquisa qualitativa em saúde. $12^{\mathrm{a}}$ ed. São Paulo: Hucitec; 2014.

6. Macedo LJ, Carvalho JB, Coutinho HRM. O gestor em saúde no setor público [Internet]. DSAU [acesso em 2013 jul 04]. Disponível em: http: / /dsau.dgp.eb.mil.br/docs/0\%20gestor\%20em\%20Sa\%C3\%Bade\%20no\%20setor\%20p\%C3 \%Bablico.pdf.

7. Silva LAA, Franco GP, Leite MT, Pinno C, Lima VML, Saraiva N. Concepções educativas que permeiam os planos regionais de educação permanente em saúde. Texto \& Contexto Enferm. 2011;20(2):340-8.

8. Manual para o gestor municipal de saúde [Internet]. Belo Horizonte; 2005[acesso em 2013 jul 04].Disponível em: http://www.saude.mg.gov.br/images/documentos/manual_gestor_municipal_sau de.pdf.

9. Andre AM, Ciampone MHT, Santelle O. Health care units and human resources management trends. Rev Saúde Pública [Internet]. 2013;47(1):158-63.

10. Melo MLC, Nascimento MAA. Treinamento introdutório para enfermeiras dirigentes: possibilidades para gestão do SUS. Rev Bras Enferm.2003;56(6):674-77.

11. Brasil. Ministério da Saúde. Secretaria de Gestão do Trabalho e da Educação na Saúde (SGTES). Departamento de Gestão da Educação na Saúde (DEGES). Política Nacional de Educação Permanente em Saúde [Internet]. Brasília; 2009 [acesso em 2016 maio 4]. (Série B. Textos Básicos de Saúde, Série Pactos pela Saúde 2006; v. 9). Disponível em: http://bvsms.saude.gov.br/bvs/publicacoes/politica_nacional_educacao_permanente_sau de.pdf.

12. Pinto S, Franco TB, Magalhães MG, organizadores. Tecendo redes: os planos da educação, cuidado e gestão na construção do sistema de saúde brasileiro: a experiência de Volta Redonda-RJ. São Paulo: Hucitec; 2012.

13. Peduzzi M, Guerra DAD, Braga CP, Lucena FS, Silva JAM. Atividades educativas de trabalhadores na atenção primária: concepções de educação permanente e de educação continuada em saúde presentes no cotidiano de Unidades Básicas de Saúde em São Paulo. Interface Comun Saúde Educ. 2009;13(30):121-34.

14. Freire P. Pedagogia da autonomia: saberes necessários à prática educativa. $43^{\mathrm{a}}$ ed. São Paulo: Paz e Terra; 2009.

15. Ceccim RB. Educação permanente em saúde e as questões permanentes à formação em saúde mental. In: Lobosque AM, organizadora. Saúde Mental: os desafios da formação. Belo Horizonte: ESP/MG.2010. p.67-90. (Caderno Saúde Mental; 3).

16. Franco TB. Produção do cuidado e produção pedagógica: produção do cuidado e produção pedagógica: integração de cenários do sistema de saúde no Brasil. Interface Comun Saúde Educ. 2007;11(23):427-38.

17. Pessanha RV; Cunha FTS. A aprendizagem-trabalho e as tecnologias de saúde na Estratégia Saúde da Família. Texto \& Contexto Enferm. 2009;18(2):233-40.

18. Montanha D. Peduzzi M. Educação permanente em enfermagem: levantamento de necessidades e resultados esperados segundo a concepção dos trabalhadores. Rev Esc Enferm USP. 2010;44(3):597-604. 


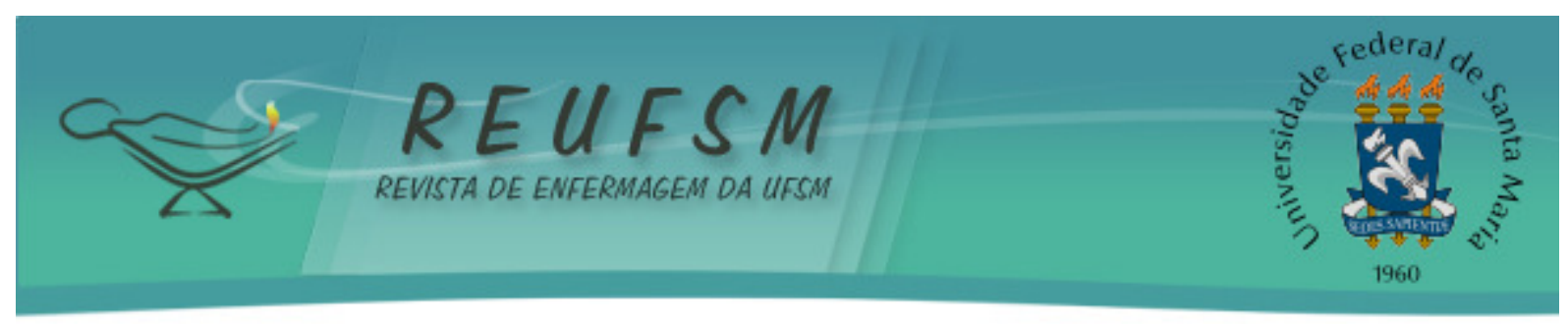

19. Ceccim RB; Feuerwerker LMC. O quadrilátero da formação para a área da saúde: ensino, gestão, atenção e controle social. PHYSIS: Rev Saúde Coletiva. 2004;14(1):41-65.

20. Brasil. Ministério da Educação. Conselho Nacional de Educação. Parecer CNE/CES nº 1.133, de 7 de agosto de 2001. Diretrizes Curriculares Nacionais dos Cursos de Graduação em Enfermagem, Medicina e Nutrição. Diário Oficial da União, Brasília; 2001 out 3. Seção $1 \mathrm{E}$, p. 131.

Data de recebimento: $28 / 10 / 2015$

Data de aceite: 24/03/2016

Contato do autor responsável: Carine Vendruscolo

Endereço postal: Rua Barão do Rio Branco, 1044 E. Jardim Italia, Chapecó/SC, CEP: 89802-101

E-mail: carine.vendruscolo@udesc.br 